\title{
Article \\ Effects of Proton Irradiation on the Current Characteristics of SiN-Passivated AlGaN/GaN MIS-HEMTs Using a TMAH-Based Surface Pre-Treatment
}

\author{
Young Jun Yoon ${ }^{1}{ }^{(}$, Jae Sang Lee ${ }^{1}$, Jae Kwon Suk ${ }^{1}$, In Man Kang ${ }^{2}$, Jung Hee Lee ${ }^{2}$, Eun Je Lee ${ }^{3}$ \\ and Dong Seok Kim ${ }^{1, *}$
}

1 Korea Multi-Purpose Accelerator Complex, Korea Atomic Energy Research Institute, Gyeongju 38180, Korea; yjyoon@kaeri.re.kr (Y.J.Y.); jslee8@kaeri.re.kr (J.S.L.); jksuk@kaeri.re.kr (J.K.S.)

2 School of Electronic and Electric Engineering, Kyungpook National University, Daegu 41566, Korea; imkang@ee.knu.ac.kr (I.M.K.); jlee@ee.knu.ac.kr (J.H.L.)

3 Advanced Radiation Technology Institute, Korea Atomic Energy Research Institute, Jeongeup 56212, Korea; leeeunje@kaeri.re.kr

* Correspondence: dongseokkim@kaeri.re.kr; Tel.: +82-054-750-5310

check for

updates

Citation: Yoon, Y.J.; Lee, J.S.; Suk, J.K.; Kang, I.M.; Lee, J.H.; Lee, E.J.; Kim, D.S. Effects of Proton Irradiation on the Current Characteristics of SiN-Passivated AlGaN/GaN MIS-HEMTs Using a TMAH-Based Surface Pre-Treatment. Micromachines 2021, 12, 864. https://doi.org/ $10.3390 / \mathrm{mi1} 2080864$

Academic Editor: Giovanni Verzellesi

Received: 5 July 2021

Accepted: 22 July 2021

Published: 23 July 2021

Publisher's Note: MDPI stays neutral with regard to jurisdictional claims in published maps and institutional affiliations.

Copyright: (C) 2021 by the authors. Licensee MDPI, Basel, Switzerland. This article is an open access article distributed under the terms and conditions of the Creative Commons Attribution (CC BY) license (https:/ / creativecommons.org/licenses/by/ $4.0 /)$.

\begin{abstract}
This study investigated the combined effects of proton irradiation and surface pre-treatment on the current characteristics of Gallium Nitride (GaN)-based metal-insulator-semiconductor highelectron-mobility-transistors (MIS-HEMTs) to evaluate the radiation hardness involved with the Silicon Nitride (SiN) passivation/GaN cap interface. The impact of proton irradiation on the static and dynamic current characteristics of devices with and without pre-treatment were analyzed with $5 \mathrm{MeV}$ proton irradiation. In terms of transfer characteristics before and after the proton irradiation, the drain current of the devices without and with pre-treatment were reduced by an increase in sheet and contact resistances after the proton irradiation. In contrast with the static current characteristics, the gate-lag characteristics of the device with pre-treatment were significantly degenerated. In the device with pre-treatment, the hydrogen passivation for surface states of the GaN cap was formed by the pre-treatment and SiN deposition processes. Since the hydrogen passivation was removed by the proton irradiation, the newly created vacancies resulted in the degeneration of gate-lag characteristics. After nine months in an ambient atmosphere, the gate-lag characteristics of the device with pretreatment were recovered because of the hydrogen recombination. These results demonstrated that the radiation hardness of MIS-HEMTs was affected by the SiN/GaN interface quality.
\end{abstract}

Keywords: Gallium Nitride (GaN); proton irradiation; surface pre-treatment

\section{Introduction}

Gallium Nitride (GaN)-based devices have received attention for high-frequency and high-power applications due to their outstanding characteristics, such as low on-resistance $\left(R_{\mathrm{on}}\right)$ and high speed, which can be realized by two-dimensional electron gas (2DEG), formed by a AlGaN/GaN heterostructure [1-3]. Moreover, high-electron mobility transistors (HEMTs) or metal-insulator-semiconductor HEMTs (MIS-HEMTs) based on the $\mathrm{AlGaN} / \mathrm{GaN}$ heterojunction have been studied for electronics in the space environments because of a remarkable radiation tolerance of $\mathrm{GaN}$ material [4-6]. Electronics used in harsh space environments must be resistant to damage or malfunctions caused by ionizing radiation. In order to evaluate radiation hardness, radiation irradiation effects on the device properties have been explored in MIS-HEMTs with various gate dielectric layers, namely, $\mathrm{SiN} / \mathrm{Al}_{2} \mathrm{O}_{3}[7,8], \mathrm{SiN}[9,10], \mathrm{Gd}_{2} \mathrm{O}_{3}$ [11], $\mathrm{MgO} / \mathrm{Sc}_{2} \mathrm{O}_{3}$ [12], and poly-AlN/SiN [13]. However, these researches have focused on the impact of dielectric on radiation resistance. The impact of the radiation on the performance of $\mathrm{GaN}$ devices dependent on the interface between passivation and the GaN layers have not been studied yet. The pre-treatment processes before the deposition passivation layer were applied to improve 
the performances of GaN-based devices. In SiN-passivated devices, the pre-treatment process is based on Tetramethylammonium(TMAH) [14], $\mathrm{NH}_{3}$ [15], $\mathrm{H}_{2} \mathrm{SO}_{4}$ [16] solutions, and $\mathrm{N}_{2}$ plasma [17] to enhance $\mathrm{SiN} /(\mathrm{Al}) \mathrm{GaN}$ interface quality because the interface quality affects device performance and reliability. The current collapse characteristics of the AlGaN/GaN heterojunction-based devices can be especially degraded by the surface state of the $(\mathrm{Al}) \mathrm{GaN}$ layer.

This study evaluated the proton irradiation effect on SiN-passivated MIS-HEMTs that use the TMAH-based pre-treatment process, which was performed to improve the SiN passivation/GaN cap interface quality. To investigate the relationship between the interface conditions and irradiation damage, we analyzed the impact of proton irradiation and the pre-treatment process on the static and dynamic current characteristics of the devices. We also verified the recovery phenomenon of the devices by re-measuring current collapse characteristics after nine months.

\section{Device Structure and Fabrication}

Figure 1a shows the schematic cross-section of the SiN-passivated AlGaN/GaN MISHEMT. The epitaxial structure was created using metal-orgranic chemical vapor deposition (MOCVD) equipment (SYSNEX, Korea) on a sapphire substrate. The device consisted of a $2 \mu$ m-thick GaN buffer layer, 60 nm-thick GaN channel layer, 22 nm-thick AlGaN layer, and $2 \mathrm{~nm}$-thick GaN cap layer. Al composition in the AlGaN layer was 0.25. Ssheet charge density of $1.42 \times 10^{13} \mathrm{~cm}^{-2}$ and mobility of $1330 \mathrm{~cm}^{2} / \mathrm{V} \cdot \mathrm{s}$ were identified using Hall-effect measurement at room temperature. The overall process flow for the fabrication and proton irradiation is shown in Figure 1b.

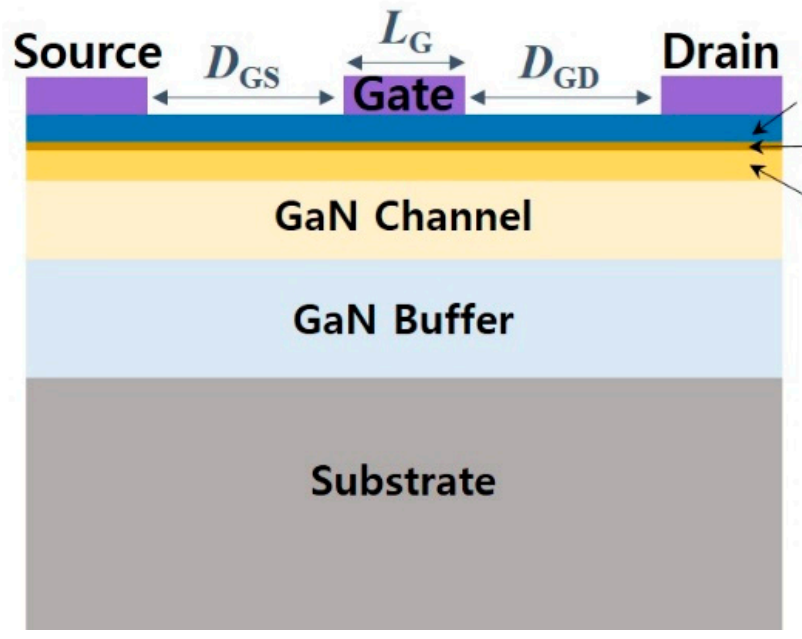

(a)

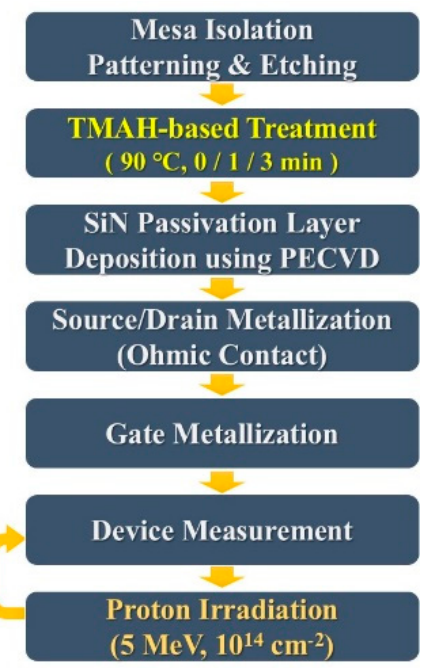

(b)

Figure 1. (a) Schematic cross-section of the SiN-passivated AlGaN/GaN metal-insulator-semiconductor high-electron mobility transistor (MIS-HEMT). (b) Process flow for the fabrication and proton irradiation.

The fabrication began with the dry etching process for electrical isolation between devices. The etched depth was about $250 \mathrm{~nm}$. The wet treatment process based on a TMAH solution ( $5 \%$ concentration) was performed at a temperature of $90^{\circ} \mathrm{C}$. The TMAH solution selectively eliminates $\mathrm{Ga}$ atoms on the surface as the alkaline solution and Ga-polar surface is terminated with $\mathrm{N}$ atoms after the treatment [18]. Thus, the TMAH-based treatment process influences the removal of native Ga-oxide and enhances the surface roughness [19]. In a previous study, we also confirmed that the TMAH treatment reduced the leakage current characteristics by effectively removing surface states on the GaN cap layer [14]. To investigate effects of the pre-treatment on the surface, we set the treatment time as 0 , 1 , and $3 \mathrm{~min}$. We used a photoresist developer containing TMAH (AZ $300 \mathrm{MIF}$ ) during the photolithography steps. However, the photoresist developer had little impact on the 
surface because the TMAH solution reacted with the GaN material at a high temperature of $\sim 90^{\circ} \mathrm{C}$. The TMAH in the photoresist developer was not significantly affected on the surface. We then deposited $20 \mathrm{~nm}$-thick $\mathrm{SiN}$ as a passivation and gate dielectric layer using plasma-enhanced chemical vapor deposition (PECVD) (SINIC, Korea) at $370{ }^{\circ} \mathrm{C}$. After the deposition of the SiN layer, source and drain contact were defined by the lithography and electron beam (e-beam) evaporator. After deposition of an $\mathrm{Au} / \mathrm{Ni} / \mathrm{Al} / \mathrm{Ti} / \mathrm{Si}$ multilayer, the metal layer was annealed using rapid thermal annealing (RTA) at $800{ }^{\circ} \mathrm{C}$ for $30 \mathrm{~s}$ in a $\mathrm{N}_{2}$ stmosphere. Finally, Ni/Al/Ni-based metallization was applied for the gate and pad. The current characteristics of completely fabricated devices were measured using a B1500 semiconductor device analyzer (Keysight, Santa Roda, California, USA). The gate length $\left(L_{\mathrm{G}}\right)$ and gate-to-source distance $\left(D_{\mathrm{GS}}\right)$ were $3 \mu \mathrm{m}$ and $5 \mu \mathrm{m}$, respectively. The gate-to-drain distance $\left(D_{\mathrm{GD}}\right)$ was designed to be $5,10,20$, and $30 \mu \mathrm{m}$. The devices were irradiated by $5 \mathrm{MeV}$ protons with a fluence of $1 \times 10^{14} \mathrm{~cm}^{-2}$ using the RFT-30 cyclotron at the Advanced Radiation Technology Institute (ARTI). After proton irradiation, the devices were measured once again. The electrical characteristics of the devices before and after proton irradiation were compared and the effects of proton irradiation and pre-treatment on performances were analyzed. We verified an injection depth of $5 \mathrm{MeV}$ protons using a simulator based on a Monte-Carlo calculation [20]. The protons with $5 \mathrm{MeV}$ energy was injected up to a depth of $125 \mu \mathrm{m}$, generating vacancies.

\section{Results and Discussion}

Figure 2 shows transfer drain current $\left(I_{\mathrm{D}}\right)$ and transconductance $\left(g_{\mathrm{m}}\right)$-gate voltage $\left(V_{\mathrm{G}}\right)$ characteristics at a drain voltage $\left(V_{\mathrm{D}}\right)$ of $10 \mathrm{~V}$ of the MIS-HEMT without and with pre-treatment for pre- and post-irradiation. The $I_{\mathrm{D}}$ and $g_{\mathrm{m}}$ characteristics of both the devices slightly decreased.

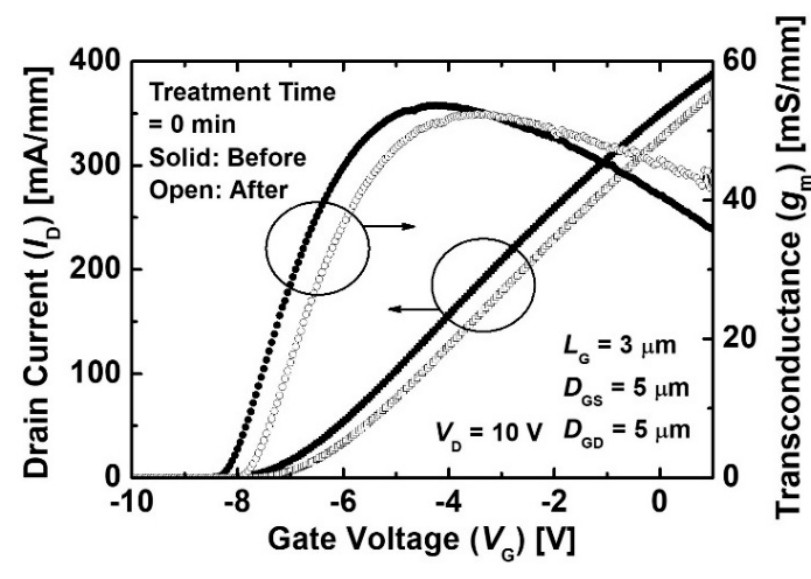

(a)

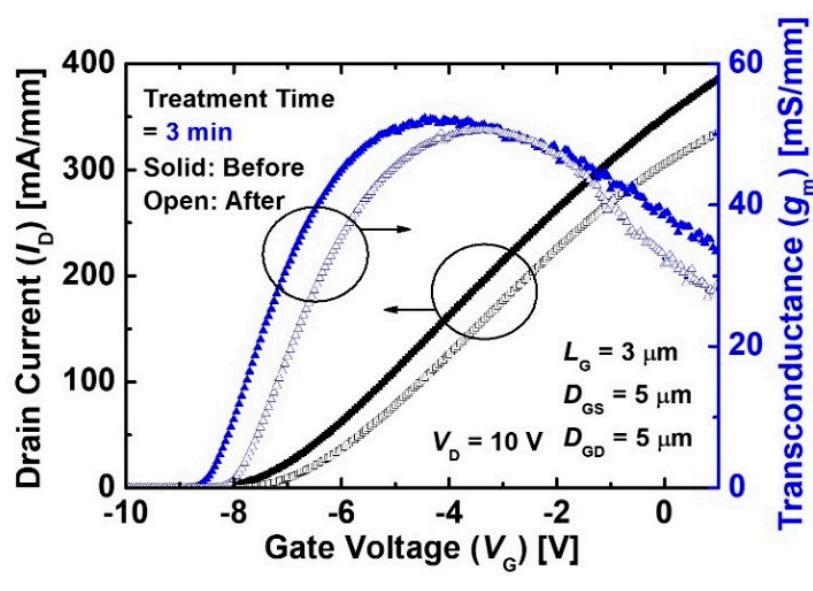

(b)

Figure 2. $I_{\mathrm{D}}$ and $g_{\mathrm{m}}$ characteristics as a function of $V_{\mathrm{G}}$ before and after $5 \mathrm{MeV}$ proton irradiation of the MIS-HEMTs (a) without treatment and (b) with treatment for $3 \mathrm{~min}$ at a $V_{\mathrm{D}}$ of $10 \mathrm{~V}$. The $L_{\mathrm{G}}, D_{\mathrm{GS}}$, and $D_{\mathrm{GD}}$ of the device were 3, 5, and $5 \mu \mathrm{m}$, respectively.

The reduced $I_{\mathrm{D}}$ and $g_{\mathrm{m}}$ was due to the increase in sheet resistance and contact, as shown in Figure 3. The contact and sheet resistances of the devices increased after the proton irradiation because the 2DEG channel and contact were damaged by the injected protons. The proton irradiation generated defects such as $\mathrm{Al}, \mathrm{Ga}$, and $\mathrm{N}$ vacancies in the 2DEG channel. The defects caused a decrease in electron mobility and 2DEG sheet carrier density $[21,22]$. More energy loss was in the ohmic contact region due to the heavier mass of the $\mathrm{Au}$ atoms. The contact metal as well as the 2DEG region nearby was damaged by more scatter protons from the collisions with heavy atoms [23]. As a result, the increase in the 2DEG channel and contact resistance were caused by radiation-induced defects. A positive shift in threshold voltage $\left(V_{\text {th }}\right)$ was observed after the proton irradiation. The $V_{\text {th }}$ 
was defined as the $V_{\mathrm{G}}$ intercept of the linear extrapolation of the $I_{\mathrm{D}}$ at the point of peak $g_{\mathrm{m}}\left(g_{\mathrm{m} \_ \text {max }}\right)$ [24], and the $V_{\text {th }}$ of all the devices were extracted at the $I_{\mathrm{D}}-V_{\mathrm{G}}$ at a low $V_{\mathrm{D}}$ of $0.1 \mathrm{~V}$. The variation rate of the $V_{\text {th }}$ values before and after the proton irradiation $\left(\Delta V_{\mathrm{th}}\right)$ of the device without the pre-treatment was about $+0.39 \mathrm{~V}$. This is consistent with the results reported in Refs. [8,9]. The proton irradiation induced reduction in electron density within the 2DEG channel due to the displacement damage $[25,26]$. As a result, the positive shift in $V_{\text {th }}$ was caused by the decreased electron density. The device with the treatment also exhibited a $V_{\text {th }}$ shift of $+0.35 \mathrm{~V}$, as shown in Figure $2 \mathrm{~b}$. These results indicate that the 2DEG channel and contact resistances were degraded by the proton irradiation, irrespective of the pre-treatment process.

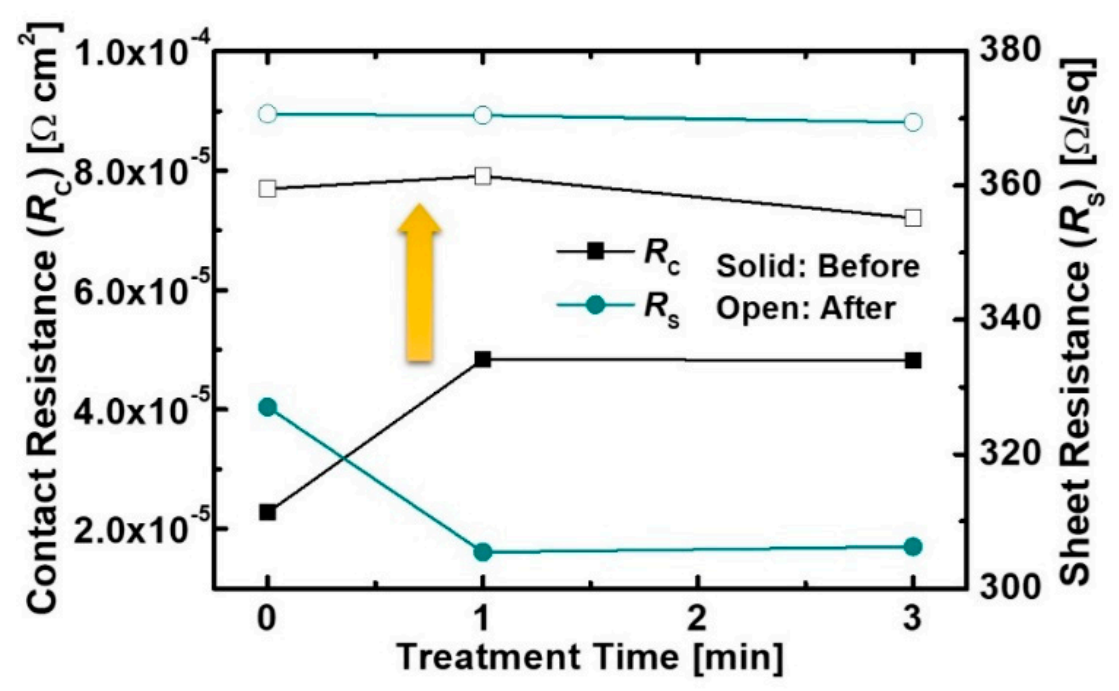

Figure 3. Sheet and contact resistances obtained from the transmission line method (TLM) of samples with and without treatment for $3 \mathrm{~min}$ before and after the proton irradiation.

Figure $4 \mathrm{a}, \mathrm{b}$ show the logarithmic scale $I_{\mathrm{D}}$ and $I_{\mathrm{G}}$ characteristics as a function of $V_{\mathrm{G}}$ before and after the proton irradiation of the MIS-HEMTs with and without the pretreatment. The off-state currents $\left(I_{\text {off }}\right)$ of both the devices were reduced more than $I_{\mathrm{G}}$. The values of $I_{\mathrm{G}}$ were affected by the value of $I_{\mathrm{off}}$. This result indicated that the decrease in $I_{\text {off }}$ was affected by the leakage current, except for the $I_{\mathrm{G}}$. The $I_{\text {off }}$ of the MIS-HEMTs was formed by leakage current paths, including a buffer layer and the surface of the mesa-etched region $[27,28]$.

We evaluated the buffer leakage current characteristics by measuring the current between ohmic contacts connecting the mesa-etched region, as shown in Figure 5a. In terms of buffer current characteristics before the irradiation, the structure with the treatment for 3 min was the lowest buffer current because of the enhanced SiN/GaN interface quality effects, as shown in Figure 5b. The buffer current was determined by the currents through the buffer layer and the SiN/GaN interface. A high buffer current of the structure without the treatment was induced by the leakage current path through the SiN/GaN interface, resulting from a large amount of surface states and traps related to the dangling bonds on the etched surface [29]. Because the treatment reduced these defects, the structure with the treatment obtained a relatively low buffer current. The structure with the treatment still exhibited the lowest buffer current of about $10^{-9} \mathrm{~A} / \mathrm{mm}$ after the proton irradiation. The buffer currents of all structures were reduced to an almost equal rate of about $10^{2}$. This result is due to the defects in the buffer generated by the proton irradiation. Because protons with an identical fluence of $1 \times 10^{14} \mathrm{~cm}^{-2}$ were injected into the buffer structure, the proton irradiation generated defects such as Ga vacancies, which increased the resistance of the buffer layer. Consequentially, the decrease in the buffer current led to the reduction in $I_{\text {off }}$ of the MIS-HEMTs, as shown in Figure 4. 


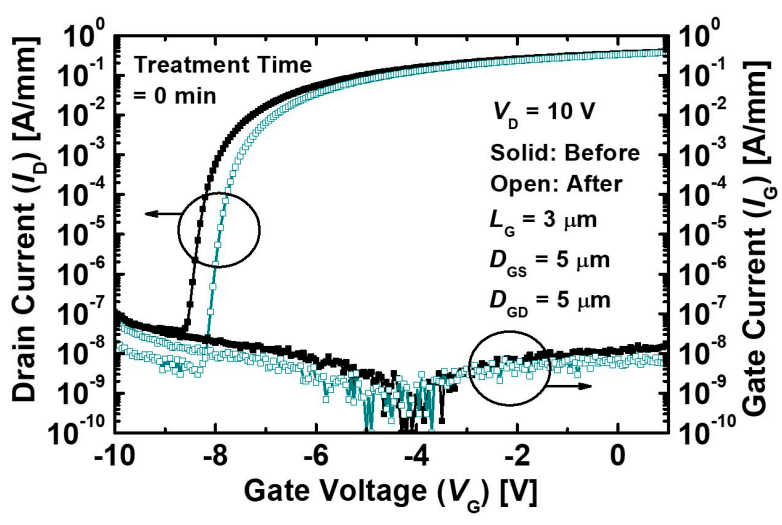

(a)

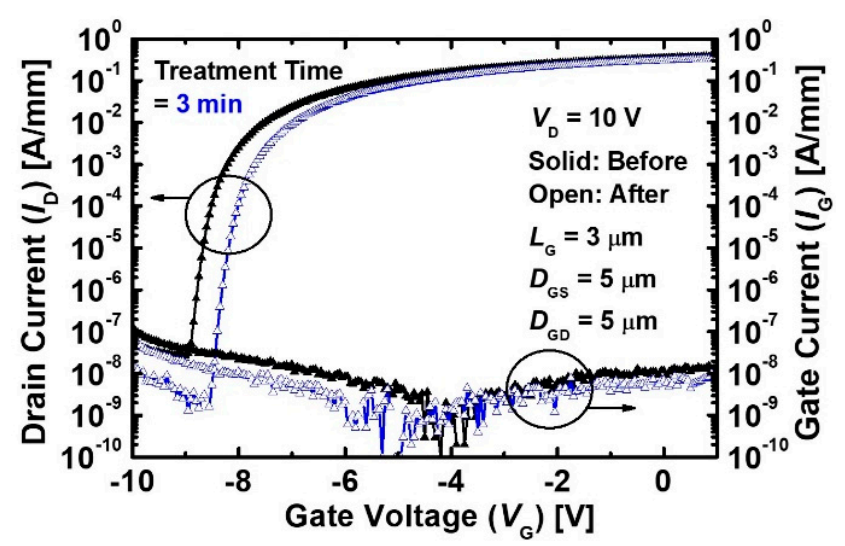

(b)

Figure 4. $I_{\mathrm{D}}$ and $I_{\mathrm{G}}$ characteristics as a function of $V_{\mathrm{G}}$ before and after the proton irradiation of the MIS-HEMTs (a) without the treatment and (b) with treatment for 3 min at a $V_{\mathrm{D}}$ of $10 \mathrm{~V}$.

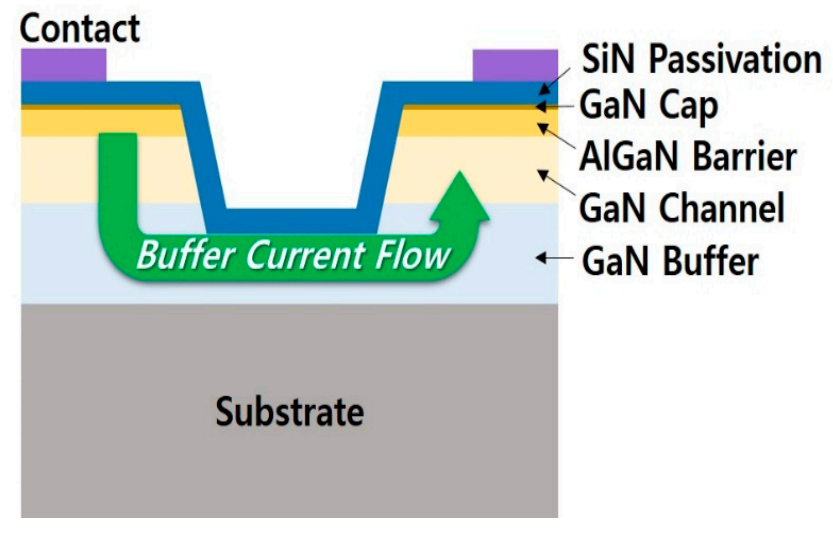

(a)

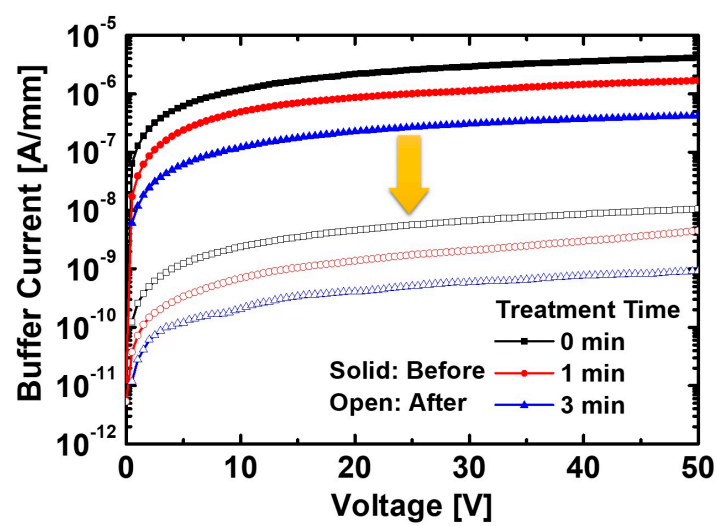

(b)

Figure 5. (a) Schematic structure for measurement of the buffer current. (b) Buffer current characteristics of the structure with and without treatment for 1 and $3 \mathrm{~min}$ before and after the proton irradiation.

Figure $6 \mathrm{a}, \mathrm{b}$ show the pulse-mode output $I_{\mathrm{D}}-V_{\mathrm{D}}$ characteristics before and after the proton irradiation of the MIS-HEMTs without and with the treatment. The quiescent bias of the gate and drain $\left(V_{\mathrm{G}_{-} \mathrm{B}}, V_{\mathrm{D}_{-} \mathrm{B}}\right)$ was $0 \mathrm{~V}$. We verified the output $I_{\mathrm{D}}-V_{\mathrm{D}}$ characteristics at the quiescent bias conditions $\left(V_{\mathrm{G}_{-} \mathrm{B}}, V_{\mathrm{D}_{-} \mathrm{B}}=0 \mathrm{~V}\right)$ to minimize the bias stress and self-heating effect [30]. The pulse period and width $\left(P_{\text {period }}\right.$ and $\left.P_{\text {width }}\right)$ in the pulse-mode measurement were $5 \mathrm{~ms}$ and $100 \mu \mathrm{s}$, respectively. The $I_{\mathrm{D}}$ of the device after the proton irradiation was lower than that before the proton irradiation. This result was due to a positive shift of $V_{\text {th }}$ as well as an increase in sheet and contact resistances. As shown in Figure 6c, all the devices exhibited higher on-resistance $\left(R_{\mathrm{on}}\right)$ after the proton irradiation than that of the devices before the proton irradiation because of the increased sheet and contact resistances. The variation of $R_{\mathrm{on}}$ as a function of $D_{\mathrm{GD}}$ exhibited a steep slope because the sheet resistance of the access region became higher [31]. This result was consistent with the transmission line method (TLM) results. 


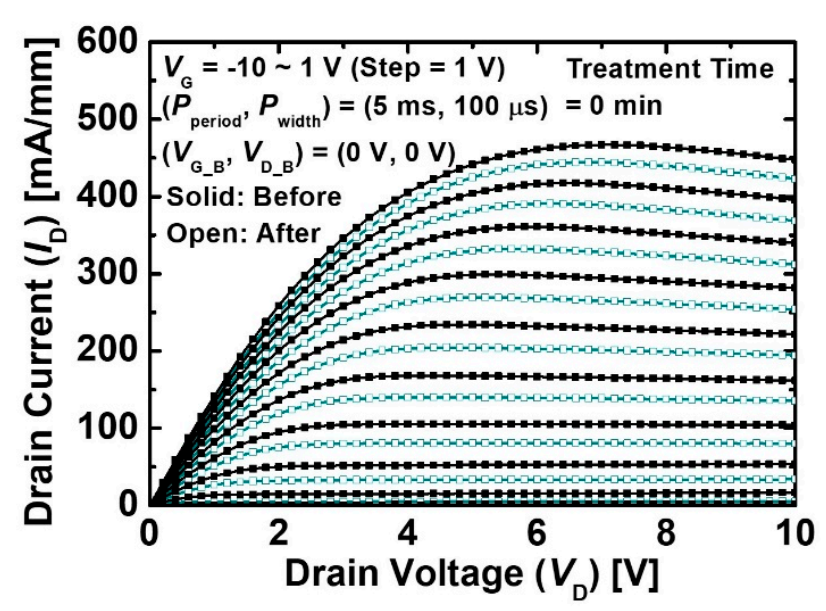

(a)

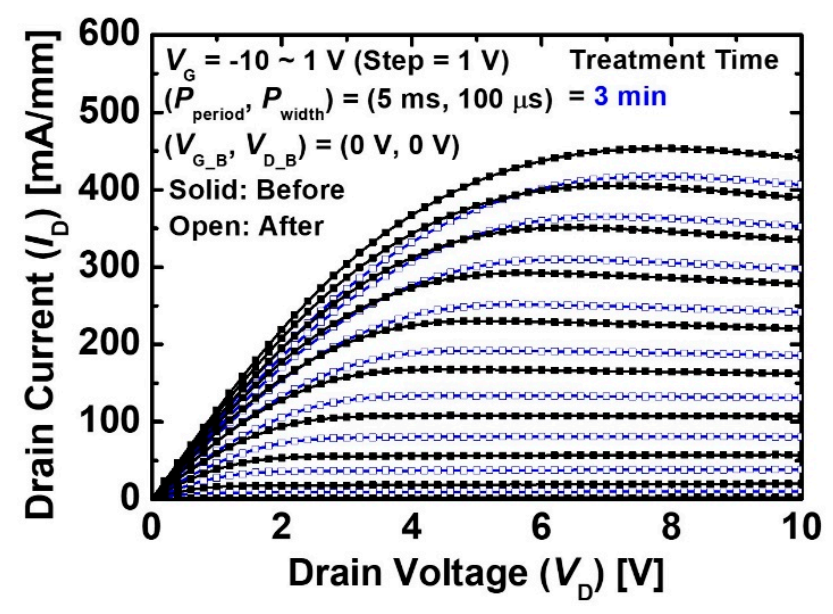

(b)

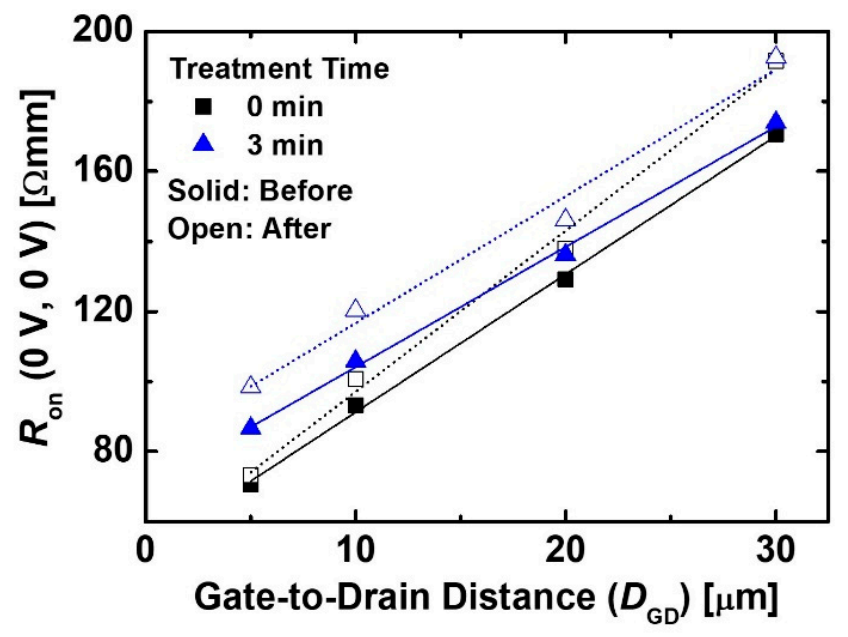

(c)

Figure 6. Pulse-mode output $I_{\mathrm{D}}-V_{\mathrm{D}}$ characteristics of the MIS-HEMTs (a) without treatment and (b) with treatment for 3 min before and after the proton irradiation. The $L_{\mathrm{G}}, D_{\mathrm{GS}}$, and $D_{\mathrm{GD}}$ of the device was 3,5 , and $5 \mu \mathrm{m}$, respectively. (c) Variation of $R_{\mathrm{on}}$ as a function of $D_{\mathrm{GD}}$. The $V_{\mathrm{G}_{-} \mathrm{B}}$ and $V_{\mathrm{D}_{-} \mathrm{B}}$ were $0 \mathrm{~V}$. The $P_{\text {period }}$ and $P_{\text {width }}$ were $5 \mathrm{~ms}$ and $100 \mu \mathrm{s}$, respectively.

Figure 7a exhibits the current collapse characteristics of the MIS-HEMTs before and after the proton irradiation. The quiescent biases of the gate and drain $\left(V_{\mathrm{G}_{\_} \mathrm{B}}, V_{\mathrm{D}_{\_} \mathrm{B}}\right)$ were $(0 \mathrm{~V}, 0 \mathrm{~V}),(-10 \mathrm{~V}, 0 \mathrm{~V}),(0 \mathrm{~V}, 20 \mathrm{~V})$, and $(-10 \mathrm{~V}, 20 \mathrm{~V})$. The pulse period and width $\left(P_{\text {period }}\right.$ and $\left.P_{\text {width }}\right)$ were $5 \mathrm{~ms}$ and $100 \mu \mathrm{s}$, respectively. Before proton irradiation, the device with the pre-treatment exhibited a relatively less impact of gate bias stress on the current characteristics because of a better quality of the SiN/GaN interface. However, as the pre-treatment time increased, the gate-lag characteristics degenerated after the proton irradiation. As shown in Figure $7 \mathrm{~b}$, the $R_{\mathrm{on}}$ variation of the device with the pre-treatment for $3 \mathrm{~min}$ were significantly increased by the irradiation. The device with the pre-treatment for 3 min exhibited more damaged on the device surface with the irradiation, as shown in the microscopic image of Figure 7c. Compared to the gate-lag characteristics, the current characteristics of all the devices were hardly changed by the drain bias stress condition. These results indicated that the SiN/GaN interface was affected by the proton irradiation. The TMAH-based pre-treatment removed native Ga-oxide from the surface of the GaN cap layer and the surface became $\mathrm{N}$-terminated. The adsorption of hydrogen can be enhanced by the N-terminated surface $[32,33]$. During the $\mathrm{SiN}$ deposition process, the surface was covered by the hydrogen in $\mathrm{SiH}_{4}$ or $\mathrm{NH}_{3}$ [34]. The hydrogen between the $\mathrm{SiN} / \mathrm{GaN}$ interface was removed by the proton irradiation, which may generate high temperature 
or displacement damage. The removal of hydrogen passivation in the SiN/GaN interface forms defects and degenerates gate-lag characteristics.

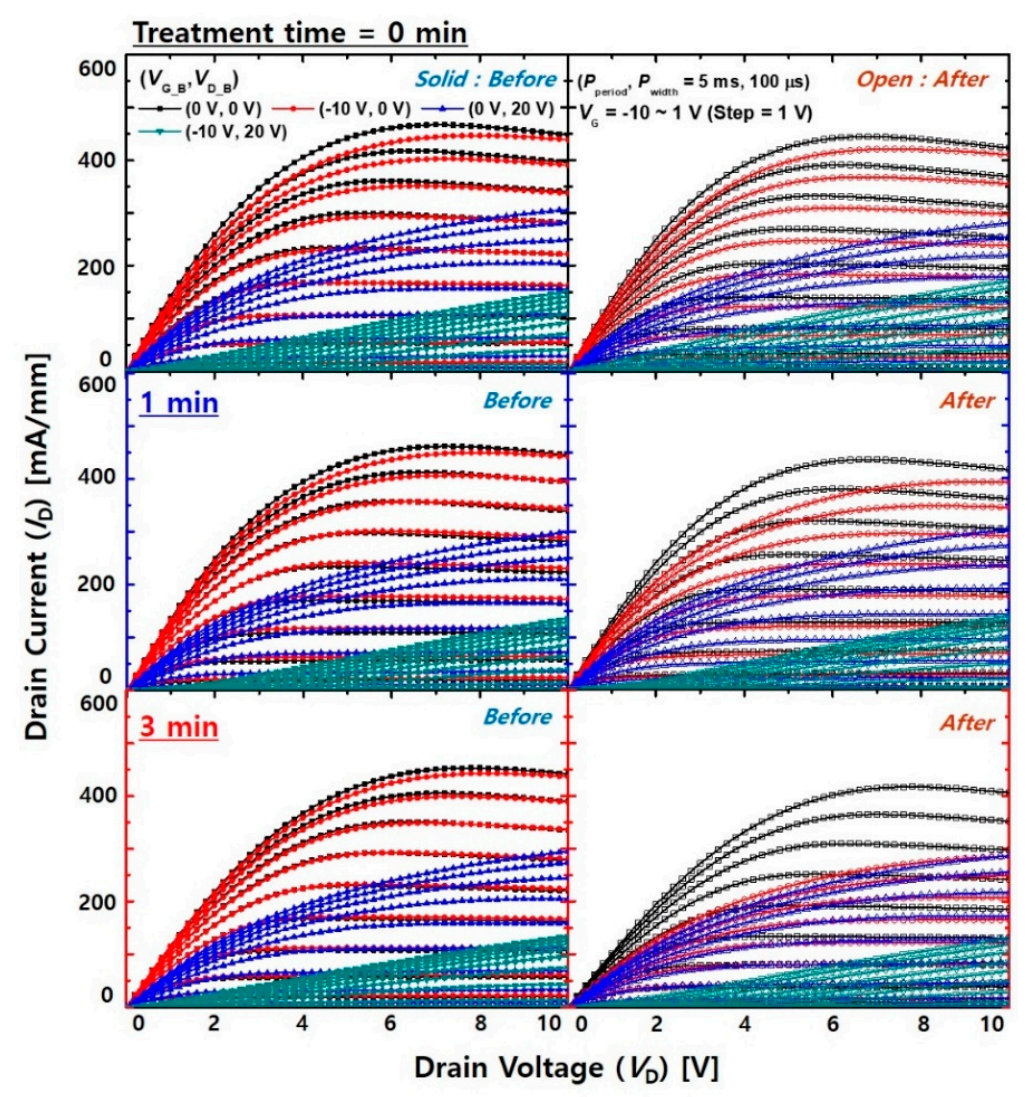

(a)

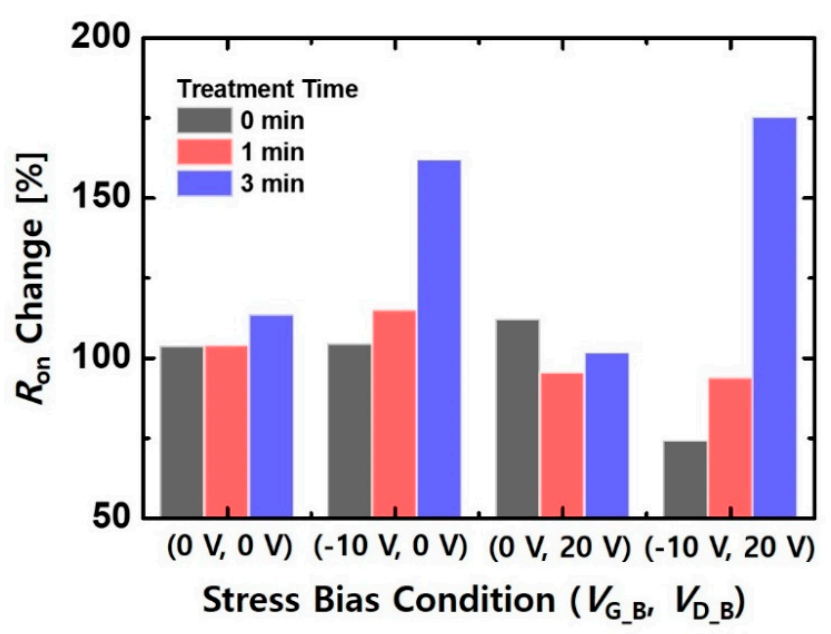

(b)

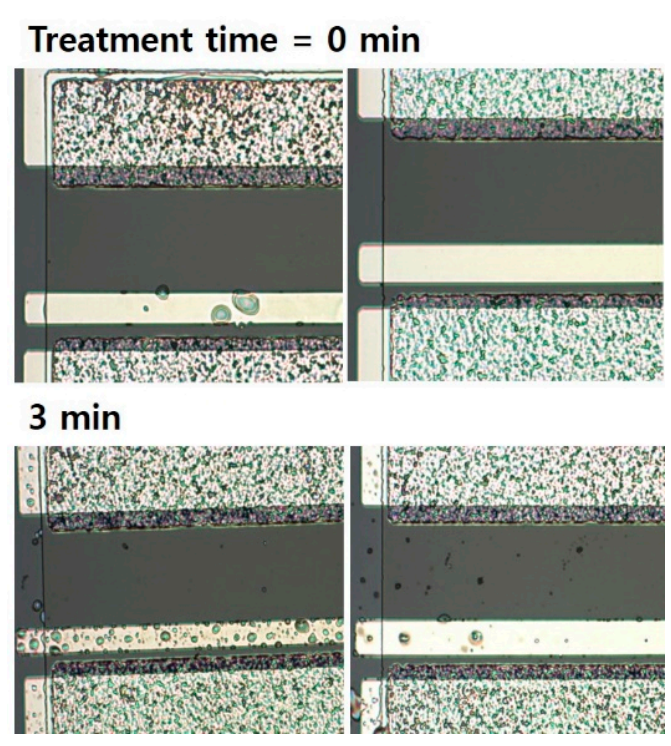

(c)

Figure 7. (a) Current collapse characteristics of the MIS-HEMTs before and after proton irradiation. (b) Variation rates of $R_{\mathrm{on}}$ depending on different stress bias conditions. The $V_{\mathrm{G}_{-} \mathrm{B}}$ and $V_{\mathrm{D} \_\mathrm{B}}$ were $(0 \mathrm{~V}, 0 \mathrm{~V}),(-10 \mathrm{~V}, 0 \mathrm{~V}),(0 \mathrm{~V}, 20 \mathrm{~V})$, and $(-10 \mathrm{~V}$, $20 \mathrm{~V}$ ). The $P_{\text {period }}$ and $P_{\text {width }}$ were $5 \mathrm{~ms}$ and $100 \mu \mathrm{s}$, respectively. The $L_{\mathrm{G}}, D_{\mathrm{GS}}$, and $D_{\mathrm{GD}}$ of the device were 3,5 , and $5 \mu \mathrm{m}$, respectively. (c) Optical microscope image after irradiation of the devices with and without treatment. 
As shown in Figure 8a, MIS-HEMTs with pre-treatment for 3 min exhibited a large increase in the rate in terms of gate-lag characteristics dependent on $D_{\mathrm{GD}}$. As $D_{\mathrm{GD}}$ increased, the device exhibited a high variation in resistance because the impact of the drain bias on trapped electrons near the gate edge was reduced by a long $D_{\mathrm{GD}}$. Figure $8 \mathrm{~b}$ shows the drain-lag characteristics of the MIS-HEMTs before and after the proton irradiation as a function of $D_{\mathrm{GD}}$. All the devices obtained a low variation rate of $R_{\mathrm{on}}$ after the proton irradiation because the $R_{\mathrm{on}}$ at $V_{\mathrm{G}_{-} \mathrm{B}}=V_{\mathrm{D}_{-} \mathrm{B}}=0 \mathrm{~V}$ was largely degraded more than $R_{\mathrm{on}}$ at $V_{\mathrm{G}_{-} \mathrm{B}}=V_{\mathrm{D} \_\mathrm{B}}=10 \mathrm{~V}$.

Figure 9 a shows the $I_{\mathrm{D}}$ and $g_{\mathrm{m}}$ characteristics as a function of $V_{\mathrm{G}}$ of the device with the pre-treatment for $3 \mathrm{~min}$ before and after proton irradiation and nine months after the irradiation. We stored the devices in an ambient atmosphere for nine months. The degenerated $I_{\mathrm{D}}$ and $g_{\mathrm{m}}$ increased after nine months while $V_{\text {th }}$ was hardly changed. Because the $g_{\mathrm{m}}$ value is associated with channel mobility [35], the current characteristics were largely recovered by the recovered mobility. The unchanged $V_{\text {th }}$ means no change in the 2DEG density. The gate-lag characteristics recovered over time, as shown in Figure $9 \mathrm{~b}$. These results indicated that the damaged $\mathrm{SiN} / \mathrm{GaN}$ interface was reconstructed by the re-passivation of hydrogen. Hydrogen was diffused from $\mathrm{SiN}$ or the atmosphere to the $\mathrm{SiN} / \mathrm{GaN}$ interface, and formed hydrogenated vacancies. The hydrogen from $\mathrm{SiN}$ and the hydrogen were able to recover the proton irradiation-generated defects [36]. Thus, the performance of the devices with the pre-treatment irradiated by the protons were recovered by the hydrogen passivation effects.

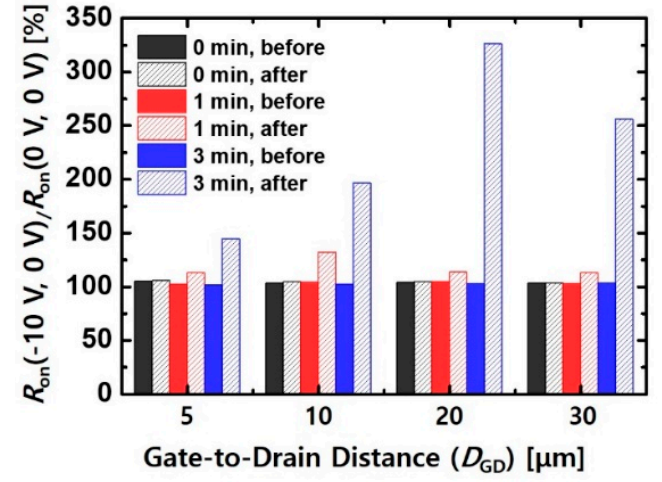

(a)

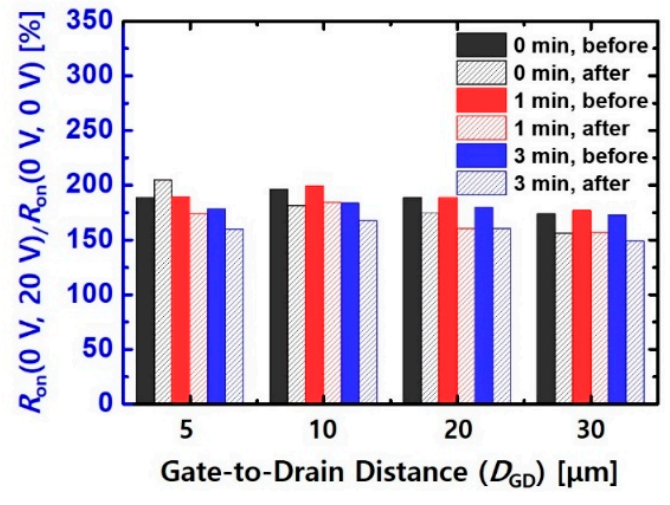

(b)

Figure 8. Variation in rates of $R_{\text {on }}$ depending on (a) gate and (b) drain stress bias conditions of the MIS-HEMTs with different values of $D_{\mathrm{GD}}$. The $P_{\text {period }}$ and $P_{\text {width }}$ were $5 \mathrm{~ms}$ and $100 \mu \mathrm{s}$, respectively.

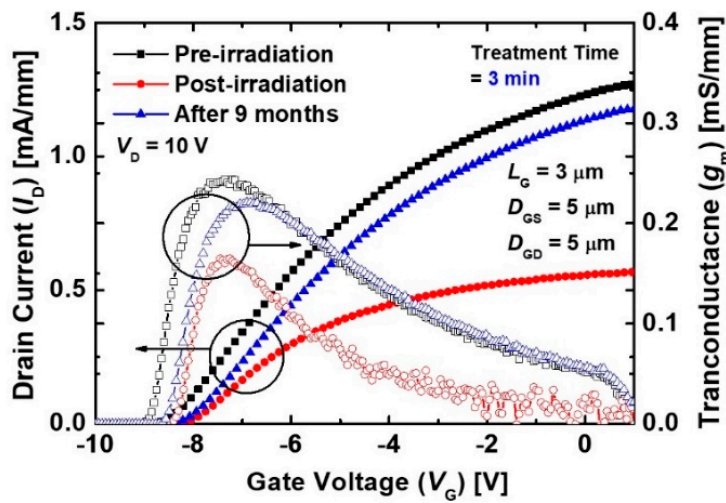

(a)

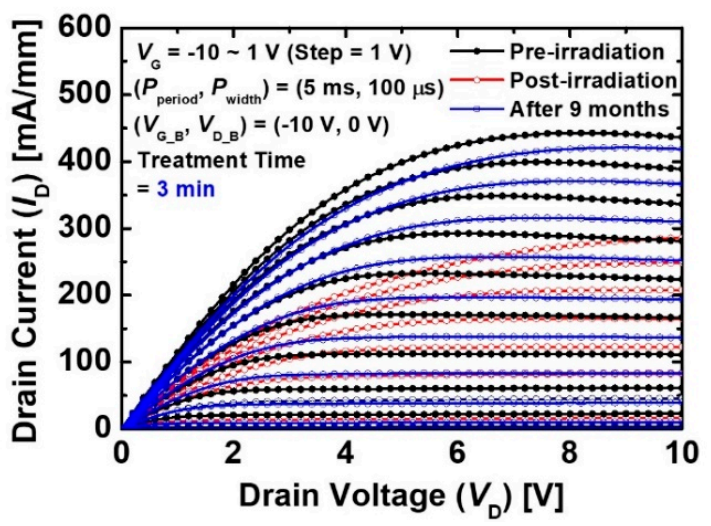

(b)

Figure 9. (a) $I_{\mathrm{D}}$ and $g_{\mathrm{m}}$ characteristics as a function of $V_{\mathrm{G}}$ at a low $V_{\mathrm{D}}$ of $0.1 \mathrm{~V}$ and (b) gate-lag characteristics of the MIS-HEMTs with treatment for 3 min before and after irradiation, and after nine months. 


\section{Conclusions}

We studied the effects of proton irradiation on SiN-passivated AlGaN/GaN MISHEMTs with a TMAH-based pre-treatment process for a fixed fluence of $1 \times 10^{14} \mathrm{~cm}^{-2}$ at a proton energy of $5 \mathrm{MeV}$. The static $I_{\mathrm{D}}$ characteristics of the devices decreased regardless of the implementation of a pre-treatment process because the increase in sheet and contact resistances was caused by radiation damage. The gate-lag characteristics of the device with the pre-treatment was remarkably degenerated after proton irradiation. The hydrogen in the SiN/GaN interface formed by the TMAH-based pre-treatment and SiN deposition process was removed by the injected protons. As a result, the degeneration of the gate-lag characteristics was induced by the generated vacancies. After nine months, the current and gate-lag characteristics of the device with pre-treatment were recovered by the hydrogen re-passivation. The results of this study confirmed that the conditions of the SiN/GaN interface affected the radiation hardness of SiN-passivated MIS-HEMTs.

Author Contributions: Conceptualization, Y.J.Y. and D.S.K.; Investigation, Y.J.Y.; data analysis, Y.J.Y., J.S.L., J.K.S., I.M.K., J.H.L., E.J.L. and D.S.K.; writing—original draft preparation, Y.J.Y.; writing-review and editing, D.S.K. All authors have read and agreed to the published version of the manuscript.

Funding: This work was supported by the KOMAC (Korea Multi-purpose Accelerator Complex) operation fund of KAERI (Korea Atomic Energy Research Institute) and the National Research Foundation of Korea (No.2018R1D1A1B07051027) by MSIT (Ministry of Science and ICT).

Conflicts of Interest: The authors declare no conflict of interest.

\section{References}

1. Mishra, U.K.; Parikh, P.; Wu, Y.-F. AlGaN/GaN HEMTs-an overview of device operation and applications. Proc. IEEE 2002, 90, 1022-1031. [CrossRef]

2. Ikeda, N.; Niiyama, Y.; Kambayashi, H.; Sato, Y.; Nomura, T.; Kato, S.; Yoshida, S. GaN Power Transistors on Si Substrates for Switching Applications. Proc. IEEE 2010, 98, 1151-1161. [CrossRef]

3. Baliga, B.J. Gallium nitride devices for power electronic applications. Semicond. Sci. Technol. 2013, $28,074011$.

4. Ionascut-Nedelcescu, A.; Carlone, C.; Houdayer, A.; Bardeleben, H.J.; Cantin, J.-L.; Raymond, S. Radiation hardness of gallium nitride. IEEE Trans. Nucl. Sci. 2002, 49, 2733-2738. [CrossRef]

5. Pearton, S.; Ren, F.; Patrick, E.; Law, M.E.; Polyakov, A.Y. Review_-Ionizing Radiation Damage Effects on GaN Devices. ECS J. Solid State Sci. Technol. 2016, 5, Q35-Q60. [CrossRef]

6. Weaver, B.D.; Anderson, T.J.; Koehler, A.D.; Greenlee, J.D.; Hite, J.; Shahin, D.I.; Kub, F.J.; Hobart, K.D. Editors' Choice-On the Radiation Tolerance of AlGaN/GaN HEMTs. ECS J. Solid State Sci. Technol. 2016, 5, Q208-Q212. [CrossRef]

7. Chang, S.-H.; Cho, K.J.; Jung, H.-W.; Kim, J.-J.; Jang, Y.-J.; Bae, S.-B.; Kim, D.-S.; Bae, Y.; Yoon, H.S.; Ahn, H.-K.; et al. Improvement of Proton Radiation Hardness Using ALD-Deposited Al2O3 Gate Insulator in GaN-Based MIS-HEMTs. ECS J. Solid State Sci. 2019, 8, Q245-Q248. [CrossRef]

8. Lee, J.-H.; Kim, D.-S.; Kim, J.-G.; Ahn, W.-H.; Bae, Y.; Lee, J.-H. Effect of gate dielectrics on characteristics of high-energy proton-irradiated AlGaN/GaN MISHEMTs. Radiat. Phys. Chem. 2021, 184, 109473. [CrossRef]

9. Fares, C.; Ren, F.; Pearton, S.; Yang, G.; Kim, J.; Lo, C.-F.; Johnson, J.W. Effect of proton irradiation energy on SiNx/AlGaN/GaN metal-insulator semiconductor high electron mobility transistors. J. Vac. Sci. Technol. B 2018, 36, 052202. [CrossRef]

10. Gao, Z.; Romero, M.F.; Redondo-Cubero, A.; Pampillon, M.A.; Andres, E.S.; Calle, F. Effects of Gd $\mathrm{d}_{2} \mathrm{O}_{3} \mathrm{Gate}_{\mathrm{Dielectric}}$ on Proton-Irradiated AlGaN/GaN HEMTs. IEEE Electron Device Lett. 2017, 38, 611-614. [CrossRef]

11. Luo, B.; Ren, F.; Allums, K.; Gila, B.; Onstine, A.; Abernathy, C.; Pearton, S.; Dwivedi, R.; Fogarty, T.; Wilkins, R.; et al. Proton irradiation of MgO- or Sc2O3 passivated AlGaN/GaN high electron mobility transistors. Solid State Electron. 2003, 47, 1015-1020. [CrossRef]

12. Zhang, D.; Cheng, X.; Shen, L.; Zheng, L.; Gu, Z.; Zhou, W.; Liu, X.; Yu, Y. Influence of Poly-AlN Passivation on the Perfor-mance Improvement of 3-MeV Proton-Irradiated AlGaN/GaN MIS-HEMTs. IEEE Trans. Nucl. Sci. 2019, 66, 2215-2219. [CrossRef]

13. He, J.; Feng, M.; Zhong, Y.; Wang, J.; Zhou, R.; Gao, H.; Zhou, Y.; Sun, Q.; Liu, J.; Huang, Y.; et al. On-wafer fabrication of cavity mirrors for InGaN-based laser diode grown on Si. Sci. Rep. 2018, 8, 7922. [CrossRef] [PubMed]

14. Yoon, Y.J.; Seo, J.H.; Cho, M.S.; Kang, H.-S.; Won, C.-H.; Kang, I.M.; Lee, J.-H. TMAH-based wet surface pre-treatment for reduction of leakage current in AlGaN/GaN MIS-HEMTs. Solid State Electron. 2016, 124, 54-57. [CrossRef]

15. Edwards, A.; Mittereder, J.; Binari, S.; Katzer, D.; Storm, D.; Roussos, J. Improved reliability of AlGaN-GaN HEMTs using an $\mathrm{NH} /$ sub 3/ plasma treatment prior to SiN passivation. IEEE Electron Device Lett. 2005, 26, 225-227. [CrossRef]

16. Zaidi, Z.H.; Lee, K.B.; Guiney, I.; Qian, H.; Jiang, S.; Wallis, D.J.; Humphreys, C.J.; Houston, P.A. Sulfuric acid and hydro-gen peroxide surface passivation effects on AlGaN/GaN high electron mobility transistors. J. Appl. Phys. 2014, 116, 244501. [CrossRef] 
17. Romero, M.; Brana, A.; Cuerdo, R.; Jimenez, A.; Miguel-Sanchez, J.; Gonzalez-Posada, F.; Gomez, F.C.; Munoz, E. Effects of N2N2 Plasma Pretreatment on the SiN Passivation of AlGaN/GaN HEMT. IEEE Electron Device Lett. 2008, 29, 209-211. [CrossRef]

18. Reddy, M.S.P.; Park, W.-S.; Im, K.-S.; Lee, J.-H. Dual-Surface Modification of AlGaN/GaN HEMTs Using TMAH and Piranha Solutions for Enhancing Current and 1/f-Noise Characteristics. IEEE J. Electron Devices Soc. 2018, 6, 791-796. [CrossRef]

19. Kim, K.-W.; Jung, S.-D.; Kim, D.-S.; Kang, H.-S.; Im, K.-S.; Oh, J.-J.; Ha, J.-B.; Shin, J.-K.; Lee, J.-H. Effects of TMAH Treatment on Device Performance of Normally Off Al2O3/GaN MOSFET. IEEE Electron Device Lett. 2011, 32, 1376-1378. [CrossRef]

20. Ziegler, J.F.; Ziegler, M.; Biersack, J. SRIM - The stopping and range of ions in matter (2010). Nucl. Instrum. Methods Phys. Res. Sect. B Beam Interact. Mater. Atoms 2010, 268, 1818-1823. [CrossRef]

21. Polyakov, A.Y.; Pearton, S.; Frenzer, P.; Ren, F.; Liu, L.; Kim, J. Radiation effects in GaN materials and devices. J. Mater. Chem. C 2012, 1, 877-887. [CrossRef]

22. Auret, F.D.; Goodman, S.A.; Koschnick, F.K.; Spaeth, J.-M.; Beaumont, B.; Gibart, P. Proton bombardment-induced electron traps in epitaxially grown n-GaN. Appl. Phys. Lett. 1999, 74, 407-409. [CrossRef]

23. Liu, L.; Cuervo, C.V.; Xi, Y.; Ren, F.; Pearton, S.J.; Kim, H.-Y.; Kim, J.; Kravchenko, I.I. Impact of proton irradiation on de performance of AlGaN/GaN high electron mobility transistors. J. Vac. Sci. Technol. B 2013, 31, 042202. [CrossRef]

24. Cai, Y.; Zhou, Y.; Lau, K.M.; Chen, K.J. Control of Threshold Voltage of AlGaN/GaN HEMTs by Fluoride-Based Plasma Treatment: From Depletion Mode to Enhancement Mode. IEEE Trans. Electron Devices 2006, 53, 2207-2215. [CrossRef]

25. Greenlee, J.D.; Specht, P.; Anderson, T.J.; Koehler, A.D.; Weaver, B.D.; Luysberg, M.; Dubon, O.D.; Kub, F.J.; Weatherford, T.R.; Hobart, K.D. Degradation mechanisms of $2 \mathrm{MeV}$ proton irradiated AlGaN/GaN HEMTs. Appl. Phys. Lett. 2015, 107, 083504. [CrossRef]

26. Kim, D.-S.; Lee, J.-H.; Kim, J.-G.; Yoon, Y.J.; Lee, J.S.; Lee, J.-H. Anomalous DC Characteristics of AlGaN/GaN HEMTs De-pending on Proton Irradiation Energies. ECS J. Solid State Sci. 2020, 9, 065005. [CrossRef]

27. Lin, Y.-S.; Lain, Y.-W.; Hsu, S. AlGaN/GaN HEMTs with Low Leakage Current and High On/Off Current Ratio. IEEE Electron Device Lett. 2009, 31, 102-104. [CrossRef]

28. Xu, Z.; Wu, W.; Ma, X.; Zhang, J.; Hao, Y.; Wang, J.; Cai, Y.; Liu, J.; Jin, C.; Yang, Z.; et al. Enhancement Mode (E-Mode) $\mathrm{AlGaN} / \mathrm{GaN}$ MOSFET With 10-1310-13 A/mm Leakage Current and 10121012 ON/OFF Current Ratio. IEEE Electron Device Lett. 2014, 35, 1200-1202. [CrossRef]

29. Liu, Z.H.; Ng, G.I.; Zhou, H.; Arulkumaran, S.; Maung, Y.K.T. Reduced surface leakage current and trapping effects in Al$\mathrm{GaN} / \mathrm{GaN}$ high electron mobility transistors on silicon with $\mathrm{SiN} / \mathrm{Al}_{2} \mathrm{O}_{3}$ passivation. Appl. Phys. Lett. 2011, 98, 113506. [CrossRef]

30. Wang, X.-D.; Hu, W.-D.; Chen, X.-S.; Lu, W. The Study of Self-Heating and Hot-Electron Effects for AlGaN/GaN Dou-ble-Channel HEMTs. IEEE Trans. Electron Devices 2012, 59, 1393-1401. [CrossRef]

31. Ohi, K.; Asubar, J.; Nishiguchi, K.; Hashizume, T. Current Stability in Multi-Mesa-Channel AlGaN/GaN HEMTs. IEEE Trans. Electron Devices 2013, 60, 2997-3004. [CrossRef]

32. Northrup, J.E.; Neugebauer, J. Strong affinity of hydrogen for the GaN(000-1) surface: Implications for molecular beam epitaxy and metalorganic chemical vapor deposition. Appl. Phys. Lett. 2004, 85, 3429-3431. [CrossRef]

33. Wang, Y.-L.; Ren, F.; Zhang, U.; Sun, Q.; Yerino, C.D.; Ko, T.S.; Cho, Y.S.; Lee, I.H.; Han, J.; Pearton, S.J. Improved hydro-gen detection sensitivity in N-polar GaN Schottky diodes. Appl. Phys. Lett. 2009, 94, 212108. [CrossRef]

34. Lelievre, J.-F.; Fourmond, E.; Kaminski, A.; Palais, O.; Ballutaud, D.; Lemiti, M. Study of the composition of hydrogenated silicon nitride SiNx:H for efficient surface and bulk passivation of silicon. Sol. Energy Mater. Sol. Cells 2009, 93, 1281-1289. [CrossRef]

35. Vitanov, S.; Palankovski, V.; Maroldt, S.; Quay, R.; Murad, S.; Rodle, T.; Selberherr, S. Physics-Based Modeling of GaN HEMTs. IEEE Trans. Electron Devices 2012, 59, 685-693. [CrossRef]

36. Chen, Z.; Yue, S.; Peng, C.; Zhang, Z.; Liu, C.; Wang, L.; Huang, Y.; Huang, Y.; He, Y.; Zhong, X.; et al. Hydrogen-Related Recovery Effect of AlGaN/GaN High-Electron-Mobility Transistors Irradiated by High-Fluence Protons. IEEE Trans. Nucl. Sci. 2021, 68, 118-123. [CrossRef] 